\title{
Uso de um compressor de ar para aquário como marcador de tempo em experimentos de cinemática
}

Using an aquarium air pump as a time marker in kinematic experiments

\author{
Roberto Hessel $^{1}$, Bruno Marconi Riboldi ${ }^{1}$, Makoto Yoshida ${ }^{1}$, Agnaldo A. Freschi*2 \\ ${ }^{1}$ Departamento de Física, Universidade Estadual Paulista "Júlio de Mesquita Filho", Rio Claro, SP, Brasil \\ ${ }^{2}$ Centro de Engenharia, Modelagem e Ciências Sociais Aplicadas, Universidade Federal do ABC, Santo André, SP, \\ Brasil
}

Recebido em 09 de Novembro, 2016. Aceito em 05 de Fevereiro, 2017.

\begin{abstract}
Neste trabalho, mostramos como construir um marcador de tempo similar àquele adotado pelo PSSC (Physical Science Study Committee) utilizando um compressor de ar para aquário e uma caneta hidrográfica. Em seguida, mostramos, também, como esse marcador pode ser utilizado tanto para registrar o movimento de um objeto a partir de pontos impressos sobre uma fita de papel presa ao objeto, como para medir intervalos de tempo com auxílio de técnicas eletrônicas para iniciar/interromper automaticamente seu funcionamento. Os experimentos sugeridos para ilustrar possíveis aplicações do dispositivo proposto permitem estudar não só as relações entre deslocamento, velocidade e tempo associadas a um movimento uniformemente variado, como também questões relacionadas com a dinâmica de translação e rotação.
\end{abstract}

Palavras-chave: Marcador de tempo, compressor de ar para aquário, caneta hidrográfica, plano inclinado.

In this paper, we show how to construct a time marker similar to that adopted by the PSSC (Physical Science Study Committee) using an aquarium air pump and a hydrographic pen. We also show how this marker can be used either to register the motion of an object from the dots printed on a paper tape attached to the object, or to measure time intervals with the aid of electronic techniques to automatically start/stop its functioning. The suggested experiments allow students to learn the relationship between displacement, velocity, and time associated with a uniformly varied motion, as well as studying the physics related to translation and rotation dynamics.

Keywords: Time marker, aquarium air pump, hydrographic pen, inclined plane.

\section{Introdução}

Atividades experimentais relacionadas com cinemática ou dinâmica requerem, normalmente, a utilização de dispositivos para medir intervalos de tempo ou para registrar a posição de um objeto em movimento a intervalos regulares. Para medir, por exemplo, o tempo necessário para um carrinho percorrer a distância entre dois pontos, podemos usar cronômetros digitais ou contadores eletrônicos alimentados por um oscilador funcionando como base de tempo e associados à chaves ópticas [1-3]. Por outro lado, para

*Endereço de correspondência: agnaldo.freschi@ufabc.edu.br se registrar a posição de um objeto em movimento a intervalos de tempo regulares podemos usar faiscadores eletrônicos e fitas de papel termo-sensível, ou a fotografia estroboscópica [3-5], ou ainda recursos mais modernos como câmeras fotográficas ou filmadoras digitais [6,7]. Mas existem, também, dispositivos mais simples como os marcadores de tempo similares àqueles utilizados pelo 'Physical Science Study Committee' (PSSC) [8] que se prestam tanto para registrar o movimento de um objeto a intervalos de tempo regulares, como para medir a duração de um evento.

Marcadores de tempo do tipo PSSC são dispositivos projetados para imprimir marcas sobre uma 
fita de papel em movimento por meio de um martelinho vibrador (lâmina vibrante) e um disco de papel carbono sob o qual corre a fita de papel. A Fig. 1 ilustra esquematicamente um modelo desse tipo alimentado por uma fonte DC (pilhas ou baterias, por exemplo).

Nesse modelo, o movimento do martelinho é gerado às custas do abrir e fechar de um platinado $(\mathrm{P}$, na Fig. 1). Quando a lâmina flexível é atraída pelo núcleo (I) da bobina energizada, o platinado abre-se e a corrente no circuito é interrompida. No retorno, o platinado fecha-se e a corrente volta a circular, estabelecendo-se, então, um movimento vibratório que faz com que o martelinho imprima marcas sobre a fita que corre debaixo do disco de carbono. A frequência de impressão sobre a fita é cerca de 50 $\mathrm{Hz}$ e depende principalmente do ajuste do platinado. Em algumas aplicações, eles são utilizados para investigar o movimento de carrinhos em experiências de cinemática e dinâmica. Neste caso, a fita é fixada no próprio carrinho em movimento. A partir dos pontos impressos na fita, pode-se então analisar como varia a distância percorrida pelo carrinho ou sua velocidade em função do tempo [8,9]. Em outras aplicações, em vez da fita ser fixada no objeto em movimento, ela é puxada pelo próprio aluno. Neste caso, o marcador, que pode ser ligado/desligado

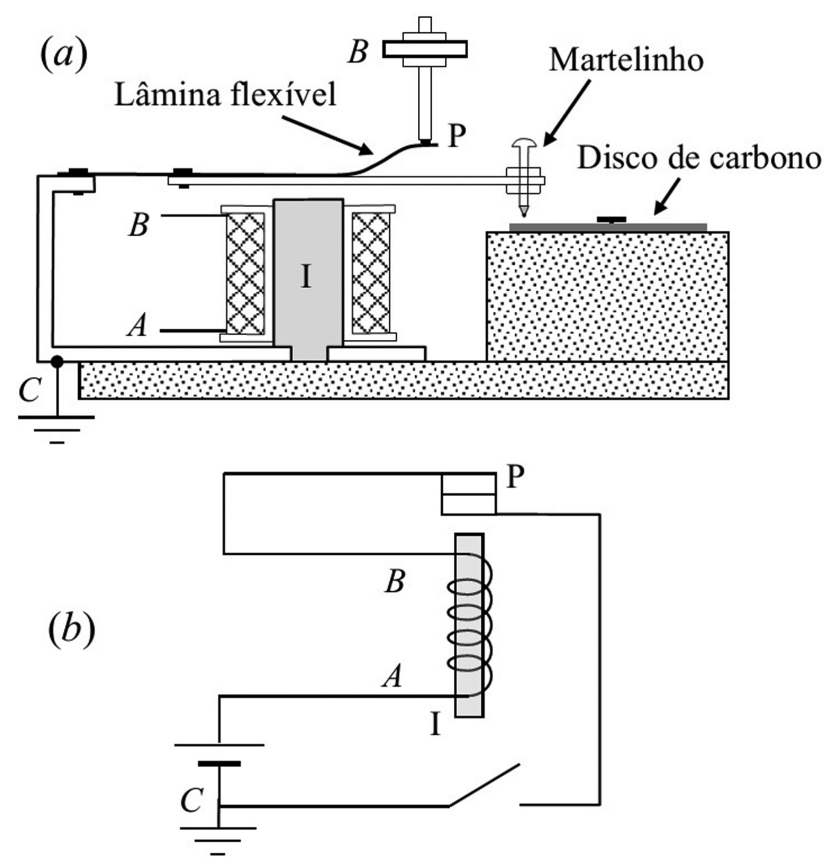

Figura 1: a) Representação esquemática do marcador de tempo adotado pelo PSSC e b) Diagrama das conexões elétricas. manual ou automaticamente, faz o papel de um cronômetro comum. Essa técnica tem sido empregada para determinar, por exemplo, a velocidade de uma esfera rolando sobre um plano horizontal [10] ou para determinar a aceleração angular de discos girantes visando o estudo da dinâmica da rotação [11].

O objetivo principal deste trabalho é mostrar, primeiramente, como um professor pode construir um marcador de tempo do tipo PSSC de baixo custo (cerca de $\mathrm{R} \$ 50,00$ ) a partir de um compressor de ar para aquário e, num segundo momento, descrever algumas aplicações não só para mostrar a versatilidade do dispositivo proposto como também para sugerir como o professor poderá explorá-lo num curso introdutório.

\section{Marcador de tempo montado a partir de um compressor de ar para aquário.}

\subsection{Funcionamento do compressor}

Um compressor de ar para aquário típico vem montado dentro de uma caixinha plástica com tampa de borracha. A Fig. 2 mostra esquematicamente a estrutura que se observa quando removemos a tampa; é uma estrutura comum a modelos de diferentes fabricantes. Ela consiste, essencialmente, num núcleo de ferro no formato de um U, uma bobina alimentada pela tensão da rede, uma câmara de borracha e uma haste com uma extremidade fixa e a outra livre para oscilar. Na dobra da extremidade livre dessa haste existe um ímã colado; para efeito de descrição, estamos supondo que é o polo norte do ímã que está colado na haste. A figura mostra também que parte de uma das laterais da caixinha foi removida para permitir a introdução do suporte de uma caneta hidrográfica que será descrito na seção seguinte.

Quando uma corrente alternada circula pela bobina, o núcleo de ferro no formato de um U se magnetiza ora num sentido ora no outro. Suponhamos que na metade positiva do ciclo da corrente, o núcleo magnetizado tenha o polo sul na sua extremidade superior e o polo norte na extremidade inferior, como indicado na figura. Se, além disso, o polo sul (S) do ímã estiver mais próximo dos polos do núcleo que o polo norte, a força resultante sobre o ímã será para baixo. Na metade negativa do ciclo da corrente, os polos invertem as posições e a força resultante sobre o ímã muda de sentido, isto é, aponta para cima. A força resultante agindo na extremidade da 


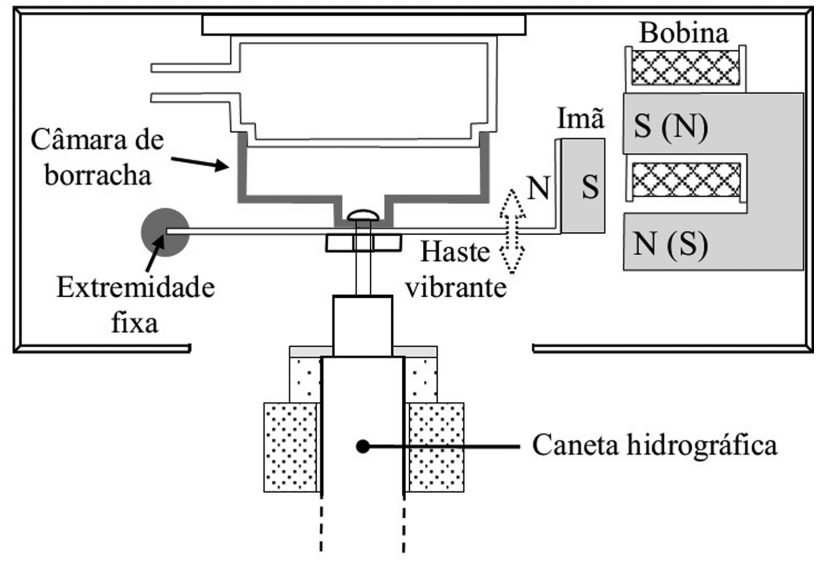

Figura 2: Vista interna de um compressor de ar para aquário típico.

haste é, portanto, uma força periódica, cujo período é o mesmo da corrente alternada que circula pela bobina. Consequentemente, sob a ação dessa força, a haste que movimenta o compressor de ar passa a executar um movimento forçado de vai-e-vem na mesma frequência da rede, ou seja, $60 \mathrm{~Hz}$ [1].

\subsection{Descrição do marcador}

Para transformar o compressor num marcador de tempo, basta transferir o movimento da haste vibratória que aciona a câmara de borracha para uma caneta hidrográfica (Fig. 2) posicionada de tal modo que possa imprimir marcas sobre uma fita de papel em movimento. Para isso, o compressor e o suporte da caneta podem ser montados numa peça de madeira no formato de um L, como mostra a Fig. 3.

O suporte da caneta é fixado por meio de um parafuso (P1) para facilitar a sua montagem ou a sua remoção após o término de um experimento. $\mathrm{O}$ compressor, por sua vez, é parafusado numa placa de madeira que pode ser deslocada ligeiramente para cima ou para baixo, pois o parafuso P2 corre dentro de um rasgo. Com isto, a ponta do parafuso que prende a haste vibrante à câmara de borracha pode ser ajustada com mais ou menos pressão sobre o topo da caneta (Fig. 2), o que permite controlar a intensidade das marcas impressas sobre a fita de papel que corre debaixo da ponta da caneta. A ponta acompanha o movimento oscilatório da haste vibrante do compressor, porque a arruela colada no topo da caneta apoia-se numa espuma que se comporta como uma mola. A amplitude de seu movimento, contudo, tem um limite graças ao degrau existente na extremidade inferior da caneta (Fig. 3).

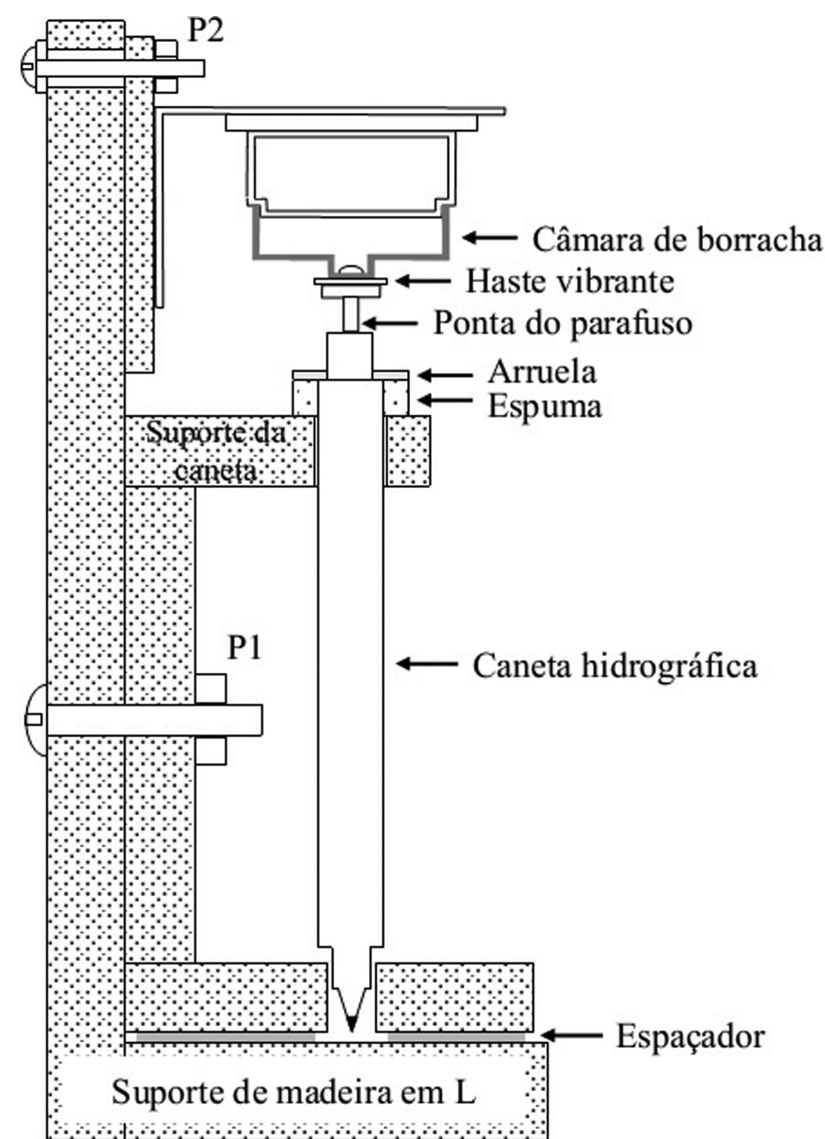

Figura 3: Esquema do marcador de tempo construído a partir de um compressor de ar para aquário e de uma caneta hidrográfica.

Essa limitação protege a ponta da caneta contra impactos violentos.

Como vimos na seção 2.1, a haste do compressor vibra na frequência da rede $(60 \mathrm{~Hz})$, o que significa que as marcas sobre a fita de papel são impressas à razão de 60 marcas por segundo. Ou seja, o tempo decorrido entre a impressão de uma marca e a seguinte é igual a 1/60 s.

\section{A análise das fitas}

Se a fita for arrastada por um carrinho, as marcas impressas sobre ela nos fornecerão uma boa descrição sobre o seu movimento. Sua análise permite várias abordagens.

\subsection{Por inspeção}

Observando-se o espaçamento entre as marcas impressas, pode-se discutir com os alunos onde a velocidade do carrinho foi maior ou menor, ou ainda 
em que trechos a velocidade cresceu, diminuiu ou permaneceu constante.

\subsection{Pelo gráfico $d$ versus $t$ ou $v$ versus $t$}

Escolhendo-se uma das marcas sobre a fita como referência, mede-se a partir dela o deslocamento $d$ do carrinho em função do tempo $t$, tomando-se, por exemplo, 1/12 s como unidade de tempo (u.t.), que é o tempo necessário para a haste do compressor executar 5 oscilações completas. A partir desses dados, constrói-se, então, o gráfico $d$ versus $t$. Verificando-se qualitativamente o comportamento da inclinação da tangente à curva em diferentes pontos dela, pode-se ter uma ideia se houve trechos da trajetória onde o movimento do carrinho foi acelerado, retardado ou uniforme. Mas, pode-se, também, com um pouco de paciência, determinar a inclinação da tangente em diferentes pontos da curva [12,13]. A partir dessas inclinações, constrói-se então o gráfico da velocidade $v$ do carrinho em função do tempo $t$.

\subsection{Pelo gráfico $v$ versus $t$ obtido a partir de $\bar{v}$ versus $t$}

Esta técnica, talvez a mais usual, consiste inicialmente em determinar a velocidade média $\bar{v}$ do carrinho em intervalos de tempo sucessivos, iguais e pequenos. Se, por exemplo, tomarmos $1 / 12 \mathrm{~s}$ como nossa unidade de tempo, então o deslocamento do carrinho durante uma unidade de tempo medido diretamente na fita será numericamente igual à velocidade média do carrinho naquele intervalo. Para construir o gráfico da velocidade média $\bar{v}$ em função do tempo $t$, basta cortar a fita em pedaços com comprimentos correspondentes à distância percorrida pelo carrinho em intervalos sucessivos e iguais e colá-los um ao lado do outro sobre uma base comum. O histograma assim construído é equivalente ao gráfico $\bar{v}$ versus $t$.

A partir desse gráfico podemos construir o gráfico da velocidade instantânea $v$ versus t, porque, para um intervalo de tempo $\Delta t=t_{2}-t_{1}$ suficientemente pequeno a velocidade média nesse intervalo é praticamente igual à velocidade instantânea no instante médio do intervalo $\left(t=\bar{t}=\left(t_{1}+t_{2}\right) / 2\right)$, ou seja, $v(t=\bar{t})=\bar{v}$ para $\Delta t$ suficientemente pequeno; geometricamente, o instante $t=\bar{t}$ corresponde ao ponto médio do segmento que representa a velocidade média em cada intervalo. Esta propriedade pode ser justificada tanto geométrica como analiticamente.
Consideremos o intervalo de tempo $\Delta t=t_{2}-t_{1}$ suficientemente pequeno para que o trecho $\mathrm{PQ}$ da curva correspondente a esse intervalo, num certo gráfico $v$ versus $t$,possa ser confundido com um segmento de reta (Fig. 4).

Nessa figura, o segmento AB horizontal representa a velocidade média do móvel no intervalo $\Delta t=$ $t_{2}-t_{1}$. Como a área sob a curva num gráfico $v$ versus $t$ representa distância percorrida, a área sob esse segmento (área do retângulo, $t_{1} A B t_{2}$ ) deve ser igual à área sob o segmento $\mathrm{PQ}$ da curva (área do trapézio $t_{1} P Q t_{2}$ ). Mas, se PQ confunde-se com um segmento de reta, a área do retângulo somente será igual à área do trapézio se a intersecção de $\mathrm{AB}$ com PQ ocorrer no ponto médio de $\mathrm{AB}$ (ou $\mathrm{PQ}$ ), que corresponde ao instante $t=\bar{t}=\left(t_{1}+t_{2}\right) / 2$.

Essa propriedade também pode ser demonstrada analiticamente. De fato, partindo da definição $\bar{v}=$ $(1 / \Delta t) \int_{t_{1}}^{t_{2}} v d t$, onde $\Delta t=t_{2}-t_{1}$, e expandindo o integrando numa série de Taylor em torno de $t=\bar{t}$, é possível mostrar que [14], $\bar{v}=v(\bar{t})+\frac{1}{2} \dot{a}(\bar{t}) \frac{(\Delta t)^{2}}{12}+$ $\frac{1}{24} \dddot{a}(\bar{t}) \frac{(\Delta t)^{4}}{80}+\cdots$, onde $\dot{a}(\bar{t})=\left.\frac{d^{2} v}{d t^{2}}\right|_{t=\bar{t}}, \dddot{a}(\bar{t})=$ $\left.\frac{d^{4} v}{d t^{4}}\right|_{t=\bar{t}}$, etc.

Se o trecho PQ na Fig. 4 puder ser confundido com um segmento de reta, a aceleração $a$ do móvel nesse intervalo será praticamente constante o que significa que $\dot{a}=\dddot{a}=0$ e que portanto, $v(t=\bar{t})=\bar{v}$.

\section{Aplicações.}

\subsection{Experimento 0 - Medida da frequência de operação do marcador.}

A frequência de operação do marcador pode ser medida de diversas maneiras. Do nosso ponto de vista,

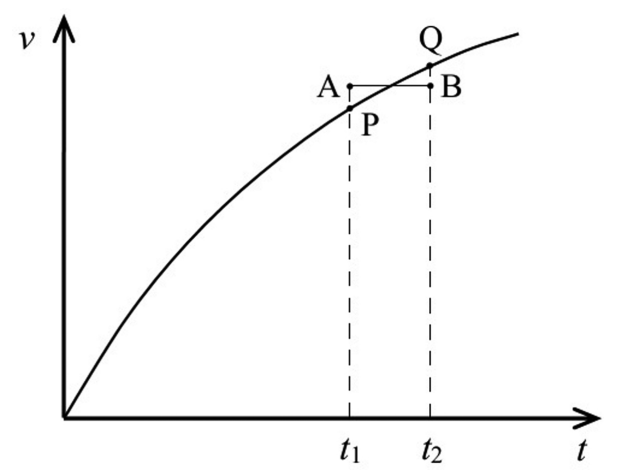

Figura 4: Gráfico aleatório de velocidade versus tempo. $\mathrm{O}$ segmento de reta $A B$ representa a velocidade média num pequeno intervalo de tempo $\Delta t=t_{2}-t_{1}$. 
a maneira mais simples e mais indicada para um curso introdutório pode ser realizada utilizando um relógio de pulso digital ou um cronômetro digital. São necessários dois alunos para realizá-la; um deles puxa a fita através do marcador enquanto o outro controla, com uma das mãos, o cronômetro e, com a outra, aciona a chave liga/desliga do marcador. $\mathrm{O}$ experimento consiste em ligar simultaneamente o marcador e o cronômetro logo depois que a fita for posta em movimento. Num dos testes que realizamos, o marcador imprimiu 706 pontos na fita (desprezando o primeiro ponto) num intervalo de $11,81 \mathrm{~s}$, o que equivale a uma frequência de impressão de 59,8 pontos/s ou $59,8 \mathrm{~Hz}$, resultado que difere menos de $0,5 \%$ do valor esperado. Este experimento é interessante porque permite determinar não só a frequência de operação do marcador como também a frequência da rede e compará-la com o valor oficial. Mas, dependendo do grau de informação dos alunos e do equipamento disponível, a frequência de operação do marcador também pode ser determinada por meio de um osciloscópio [15] ou utilizando dois contadores eletrônicos, como descrito na Ref. 1.

\subsection{Experimento 1 - Análise do movimento de um cilindro rolando para baixo sobre um plano inclinado.}

O objetivo deste experimento é analisar o movimento de um cilindro rolando para baixo sobre um plano inclinado. Para isso, prendemos a fita num suporte leve atrelado ao cilindro (Fig. 5) e fixamos o marcador no plano inclinado.

A Fig. 6 mostra os gráficos $\bar{v}$ versus $t$ e $v$ versus $t$ obtidos a partir de uma fita puxada por um cilindro de $702 \mathrm{~g}$ ao rolar sobre um plano com uma inclinação de aproximadamente $6,5^{\circ}$, tomando como unidade de tempo $1 / 12 \mathrm{~s}$ e desprezando os primeiros pontos

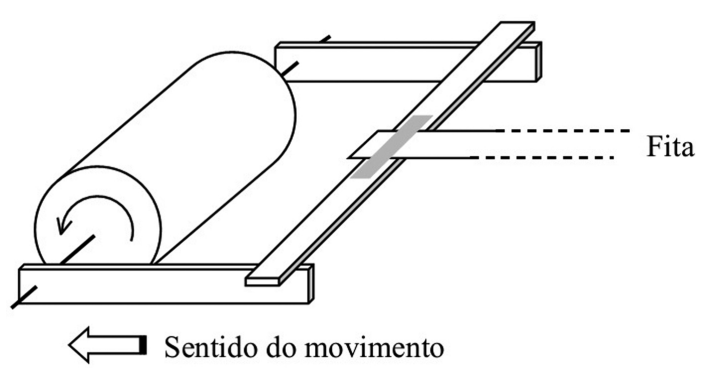

Figura 5: Esquema de um suporte leve atrelado a um cilindro que rola num plano inclinado.

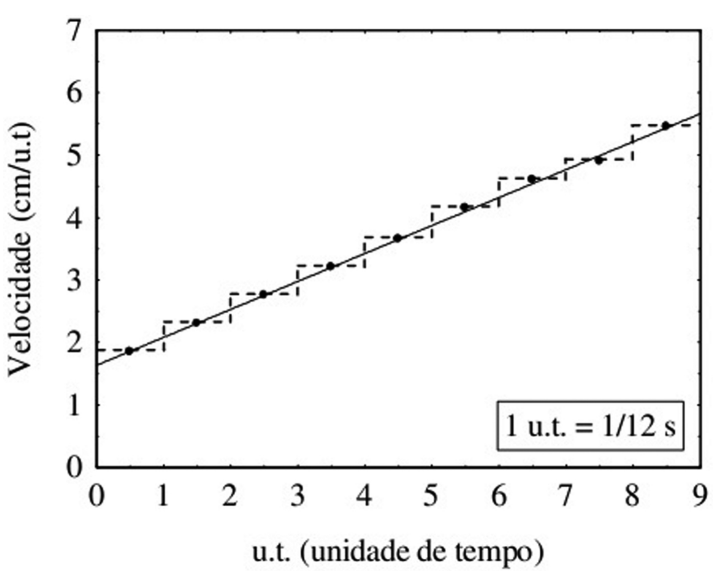

Figura 6: Velocidade de um cilindro rolando para baixo sobre um plano inclinado em função do tempo. A linha cheia representa a curva de velocidade instantânea obtida a partir das velocidades médias do cilindro (linhas tracejadas) medidas em intervalos de tempo de $1 / 12 \mathrm{~s}$.

impressos sobre a fita. Ao construir o gráfico $v$ versus $t$, admitimos que a velocidade instantânea $(v)$ no instante médio de um intervalo de $1 / 12 \mathrm{~s}$, que pode ser considerado suficientemente pequeno neste caso, coincide com a velocidade média $(\bar{v})$ nesse intervalo (ver seção 3.3.) Este gráfico nos diz que o movimento desse cilindro é uniformemente acelerado.

A inclinação da reta nesse gráfico, igual a 0,448 $\mathrm{cm} /(\text { u.t })^{2}=64,5 \mathrm{~cm} / \mathrm{s}^{2}$, corresponde à aceleração do cilindro. Por outro lado, a 'área' do trapézio com altura de 8,0 u.t., base menor de 1,6 cm/u.t. e base maior de $5,2 \mathrm{~cm} /$ u.t. mede $27,2 \mathrm{~cm}$, enquanto a distância percorrida pelo carrinho desde $t=0$ até o instante $t=8,0$ u.t., medida diretamente na fita, é igual a $27,4 \mathrm{~cm}$. Dentro do erro experimental esses valores podem ser considerados praticamente iguais, como se esperava.

Se, por alguma razão, suspeitarmos que o movimento do cilindro ao rolar sobre o plano inclinado é uniformemente acelerado, a análise dos dados admitirá outra abordagem. De fato, da equação $d=v_{0} t+(1 / 2) a t^{2}$ segue que $d / t=v_{0}+(1 / 2) a t[16]$. Se a nossa suspeita estiver correta, o gráfico $d / t$ versus $t$ deverá necessariamente resultar numa reta cuja inclinação será igual à metade da aceleração do cilindro; a distância percorrida pelo cilindro em função do tempo é medida diretamente na fita de papel. O gráfico mostrado na Fig. 7 confirma que o movimento do cilindro rolando sobre o plano inclinado é de fato uniformemente acelerado. Além disso, a inclinação da reta $\left(33,2 \mathrm{~cm} / \mathrm{s}^{2}\right)$ é praticamente a metade da aceleração $\left(64,5 \mathrm{~cm} / \mathrm{s}^{2}\right)$ determinada a 


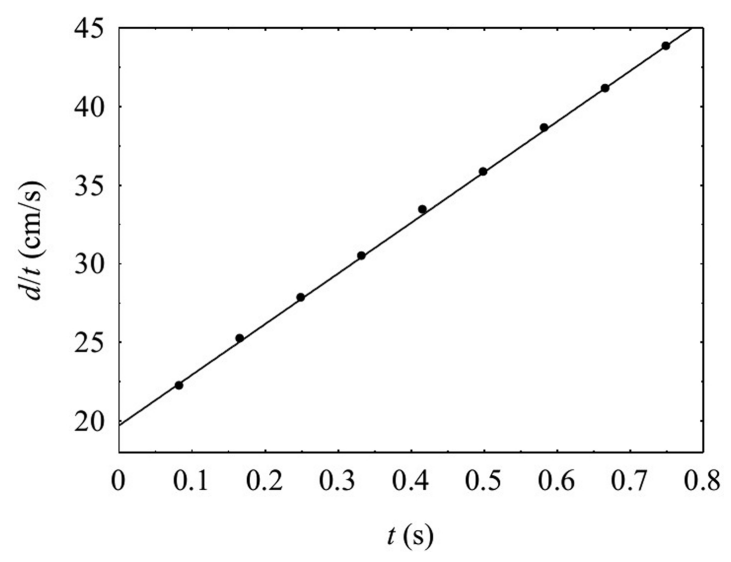

Figura 7: Evolução temporal da razão d/t (distância percorrida sobre o tempo) de um cilindro rolando para baixo sobre um plano inclinado. Os pontos representam os dados experimentais e a linha cheia corresponde ao ajuste linear.

partir do gráfico $v$ versus $t$ (Fig. 6) e a velocidade $v_{0} \cong 20 \mathrm{~cm} / \mathrm{s}$ coincide, dentro do erro experimental, com aquela lida no mesmo gráfico, como se esperava.

A mesma montagem pode também ser utilizada para analisar o movimento de um carrinho descendo o plano inclinado. Neste caso, o aluno poderá observar que a aceleração do cilindro rolando sobre o plano é menor que a aceleração do carrinho descendo o mesmo plano e cerca de $2 / 3$ da aceleração do carrinho, como previsto pela teoria [17]. Por exemplo, usando um carrinho de aproximadamente $900 \mathrm{~g}$, obtivemos para a aceleração o valor de $95,1 \mathrm{~cm} / \mathrm{s}^{2}$ enquanto a aceleração do cilindro rolando resultou igual a $64,5 \mathrm{~cm} / \mathrm{s}^{2}$. A razão $64,5 / 95,1 \cong 0,68 \cong 2 / 3$. Esse resultado é satisfatório, se considerarmos que não levamos em conta $i$ ) a resistência que a fita opõe ao movimento tanto do cilindro como do carrinho, ii) o atrito dos rolamentos com os eixos do carrinho e iii) o momento de inércia dos rolamentos, por exemplo.

\subsection{Experimento 2 - Medida da velocidade de uma esfera rolando num plano horizontal.}

Nesta experiência, uma pequena esfera de aço passa com velocidade $v$ por duas chaves montadas sobre uma superfície horizontal (Fig. 8) depois de ser abandonada de certa altura numa rampa.

As chaves, feitas com tiras de papel alumínio, estão representadas esquematicamente na Fig 9 e podem ser coladas na superfície (retalho de forro de $\mathrm{PVC}$, por exemplo). Os terminais (fios cabinho) X,Y

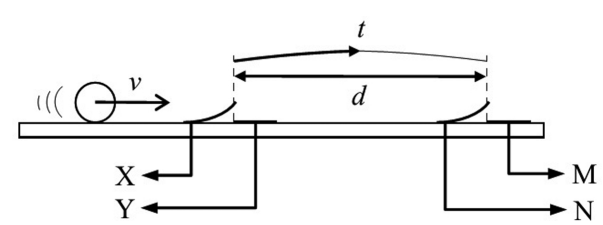

Figura 8: Montagem para medir a velocidade de uma esfera rolando sobre um plano horizontal.

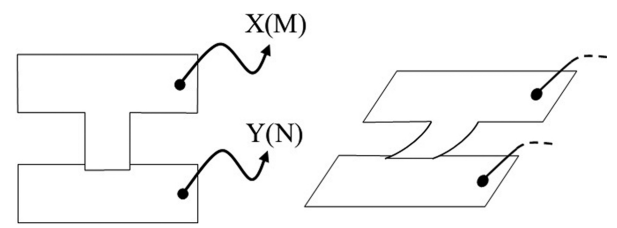

Figura 9: Chave de papel alumínio quando vista de cima (esquerda) e em perspectiva (direita).

e M,N são fixados sobre as tiras de papel alumínio com fita adesiva.

$\mathrm{O}$ contato entre $\mathrm{X}$ e $\mathrm{Y}$ (ou $\mathrm{M}$ e $\mathrm{N}$ ) é feito quando a esfera passa sobre as tiras. As extremidades livres dos terminais são conectadas aos pontos correspondentes indicados no circuito da Fig. 10.

Esse circuito é composto por dois blocos: I e II. O bloco I contem o marcador alimentado pela tensão da rede, um interruptor e um resistor variável (potenciômetro de $5 \mathrm{k} \Omega$ ) em paralelo com um relê que dispõe de um contato normalmente fechado (NF) e outro normalmente aberto (NA) acionados por uma bobina alimentada por uma fonte de $5 \mathrm{~V}$; para a experiência descrita neste item, usamos apenas os terminais correspondentes ao contato normalmente aberto. A função do resistor variável é controlar a amplitude de oscilação da lâmina vibrante do compressor. Antes de iniciar o experimento, zeramos a resistência do resistor e ajustamos a distância da ponta da caneta (Fig. 3) em relação à fita de papel até que a impressão das marcas sobre a fita alcance a intensidade desejada. Em seguida, variamos a resistência do resistor até que a impressão desapareça, isto é, que a ponta da caneta não mais toque a fita. Assim, com o contato do relê aberto (bobina não energizada) a amplitude da vibração da lâmina é pequena; com ele fechado (bobina energizada) o resistor permanece curto-circuitado e a amplitude volta para o seu valor original, pois a corrente pelo marcador é máxima (33 mA, no nosso caso). Resumindo: no início de um experimento, o marcador é ligado, mas permanece vibrando com baixa ampli- 


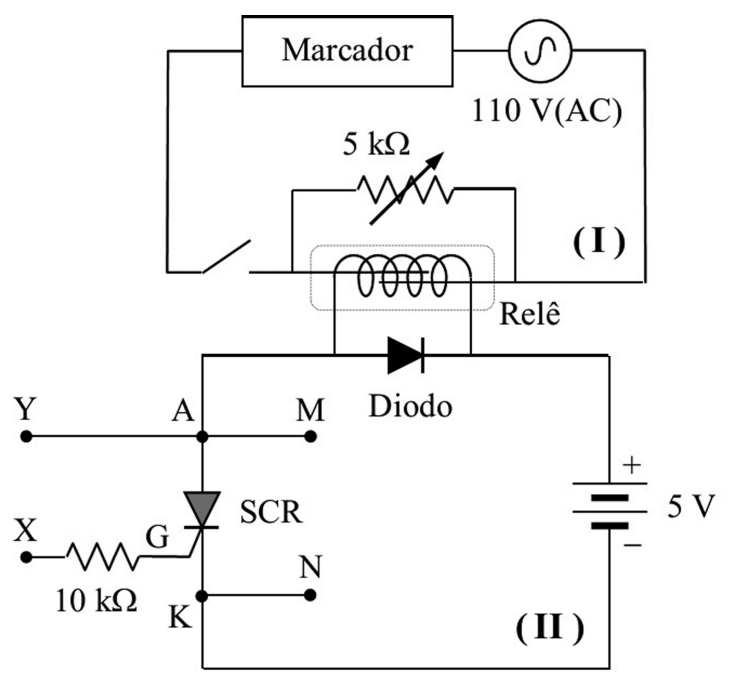

Figura 10: Circuito utilizado para medir o tempo necessário para uma esfera rolando num plano horizontal percorrer a distância entre duas chaves de alumínio.

tude, isto é, em regime de espera. A impressão das marcas sobre a fita só ocorrerá a partir do momento em que o resistor limitador for curto-circuitado; com o marcador funcionando em regime de espera, evitamos o atraso na impressão da primeira marca na fita, porque o esforço para vencer a inércia do compressor de ar ao ser ligado é menor do que seria se não procedêssemos dessa forma. Com esse artifício, a qualidade dos dados melhora.

O dispositivo básico no bloco II da Fig. 10 é o SCR; ele tem como característica só permitir a passagem da corrente depois que o terminal G ("gate") receber um pulso de tensão. Uma vez estabelecida a corrente através dele, ela só pode ser interrompida se a fonte for desligada ou se os pontos A e K entrarem em contato momentaneamente [18].

Quando a esfera passa pela primeira chave, os terminais $\mathrm{X}$ e $\mathrm{Y}$ entram em contato momentaneamente e $\mathrm{G}$ recebe um pulso, porque o potencial de Y é o mesmo do terminal positivo da fonte enquanto não há corrente no circuito. Com isso, o SCR libera a passagem da corrente, a bobina é energizada e o campo magnético gerado no seu interior fecha o contato que estava aberto, curto-circuitando o resistor limitador. A caneta começa, então, a imprimir marcas sobre a fita puxada por um dos componentes da equipe. Quando a esfera passar pela segunda chave, $\mathrm{M}$ e $\mathrm{N}$ entrarão em contato momentaneamente e o SCR interromperá a corrente que circula pela bobina. Com isso, o contato do relê abre-se e a impressão das marcas sobre a fita cessa; quando a bobina é desenergizada surge nela uma força contra- eletromotriz que pode prejudicar o SCR. Para evitar que isso ocorra, instala-se um diodo em paralelo com a bobina.

O número de intervalos entre as marcas impressas na fita corresponde ao tempo $t$ que a esfera leva para percorrer a distância $d$ entre as chaves de alumínio da Fig. 8. A velocidade $v$ da esfera será dada então pela razão $d / t$. Essa montagem foi utilizada para realizar a experiência descrita a seguir.

\subsection{Experimento 3 - Velocidade adquirida por uma esfera na base de um plano inclinado em função da altura da qual foi liberada.}

Quando uma esfera de massa $m$ e raio $R$ é liberada de uma altura $h$ numa rampa, parte de sua energia potencial gravitacional $(m g h)$ é transformada em energia associada ao movimento de translação de seu centro de massa (energia cinética de translação) e parte em energia associada a sua rotação (energia cinética de rotação). Supondo que não haja escorregamento e que a energia total é conservada, vale a relação $m g h=m v^{2} / 2+I \omega^{2} / 2$, onde $h$ é o deslocamento vertical da esfera desde sua posição inicial até a base do plano inclinado, $v$ é a velocidade do seu centro de massa, $I=2 m R^{2} / 5$ é o seu momento de inércia e $\omega=v / R$. Dessas expressões, resulta $v^{2}=10 / 7 g h$ ou

$$
v^{2}=\frac{10 g \sin \theta}{7} d
$$

uma vez que $h=d \sin \theta$, onde $\theta$ é a inclinação do plano.

Esse resultado pode ser verificado experimentalmente utilizando-se o circuito descrito no item 4.3 e a rampa da Fig. 11, construída a partir de um retalho de forro de PVC. O procedimento experimental consiste em deslocar o bloco nessa figura para diferentes posições e medir a velocidade da esfera em função da distância $d$ indicada na figura. $\mathrm{O}$ gráfico na Fig. 12 ilustra um dos resultados obtidos, variando $d$ entre 10 e 40 centímetros. Se desprezarmos pequenas perdas de energia cinética durante o movimento, podemos concluir que realmente $v^{2}$ é proporcional a $d$, como previsto. Além disso, a inclinação da reta $\left(175,3 \mathrm{~cm} / \mathrm{s}^{2}\right)$ concorda razoavelmente bem com o valor determinado a partir da expressão $(10 / 7) g \sin \theta$. De fato, considerando $g=$ $976 \mathrm{~cm} / \mathrm{s}^{2}$ e o valor medido para $\theta$, que é igual a 


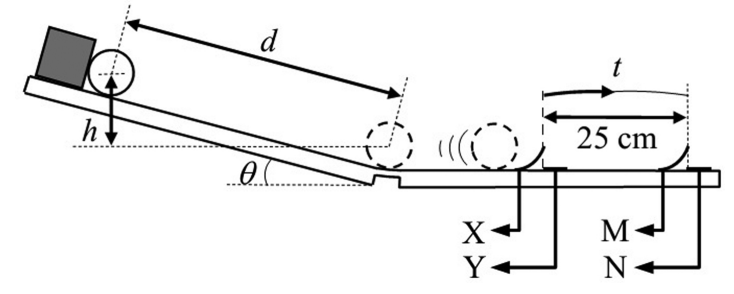

Figura 11: Arranjo experimental para medir a velocidade alcançada por uma esfera na base de um plano inclinado após ser liberada de uma altura h.

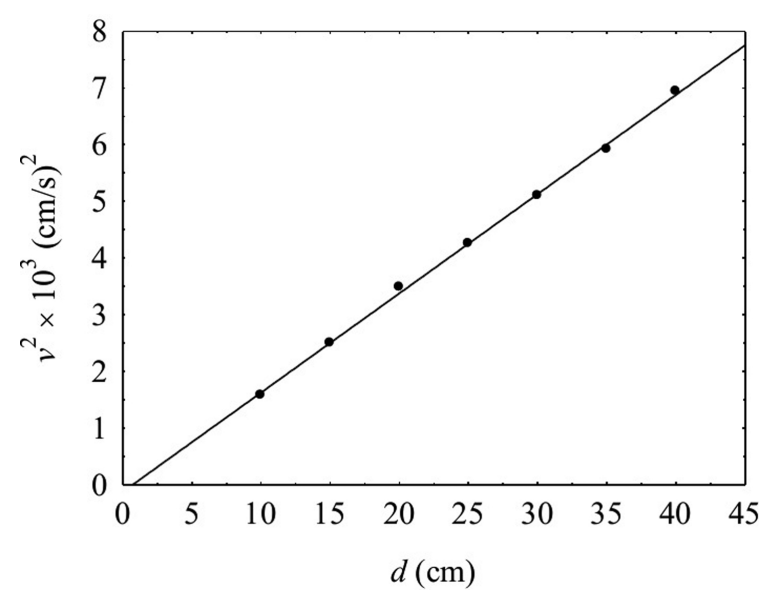

Figura 12: Quadrado da velocidade de uma esfera rolando sobre um plano inclinado a partir do repouso em função da distância percorrida sobre o plano. Os pontos representam os dados experimentais e a linha cheia corresponde ao ajuste linear.

$(7,1 \pm 0,1)$ graus, obtemos $172,3 \mathrm{~cm} / \mathrm{s}^{2} ;$ a diferença entre os dois valores é cerca de $2 \%$.

O objetivo deste experimento pode ser ampliado, ou seja, não precisamos nos limitar a uma simples confirmação da validade de uma expressão. O professor pode, por exemplo, chamar a atenção de seus alunos para o fato da inclinação da reta na Fig. 12 (ou a constante de proporcionalidade na Eq. (1)) ter dimensão de aceleração. Consequentemente, o movimento da esfera deve ser uniformemente acelerado e obedecer à equação de Torricelli. Essa inclinação, portanto, deve corresponder ao dobro da aceleração da esfera, o que significa dizer que a aceleração da esfera será igual a $5 / 7 g \sin \theta$. Essa conclusão poderá ser confirmada posteriormente utilizando as leis da dinâmica da rotação [17].

\subsection{Experimento 4-Análise do movimento de uma esfera enquanto desce rolando sobre um plano inclinado.}

O objetivo desta experiência é mostrar que o movimento do centro de massa de uma esfera rolando para baixo sobre um plano inclinado é uniformemente acelerado. Para isso, diferentemente do que fizemos no experimento anterior, vamos analisar a distância percorrida e a velocidade alcançada pela esfera em função do tempo de descida. A montagem utilizada está mostrada na Fig. 13. A chave $\mathrm{CH} 2$, feita com papel alumínio, é fixa e foi montada na mesma posição que serviu de origem para medida da distância $d$ na Fig. 11. A chave CH1, por sua vez, é montada num anteparo móvel e isolante.

A Fig. 14 mostra o anteparo visto de cima com os dois parafusos que fazem o papel dos terminais de $\mathrm{CH} 1$; a chave fecha quando a esfera metálica encosta nos parafusos e abre quando ela abandona o anteparo.

A experiência consiste em medir, para certa distância $d$, o intervalo de tempo $t$ indicado na Fig. 13. Para isso, a impressão das marcas na fita deve começar imediatamente após a esfera abandonar o anteparo e ser interrompida quando passar por CH2. Isso pode ser feito substituindo no circuito esquematizado na

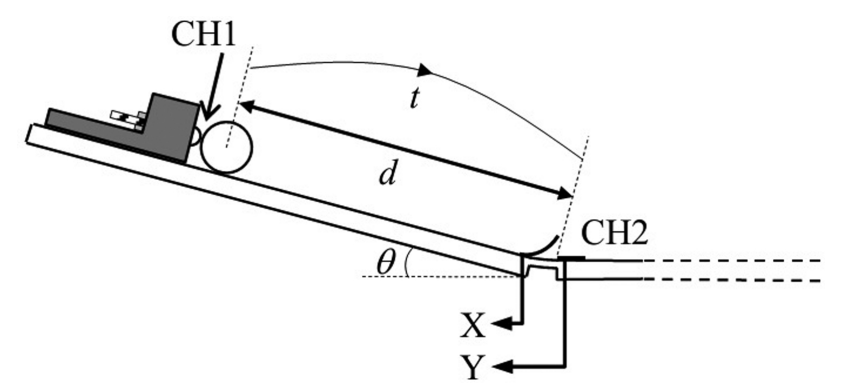

Figura 13: Arranjo experimental para medir o tempo $t$ necessário para uma esfera percorrer a partir do repouso uma distância d sobre o plano inclinado.

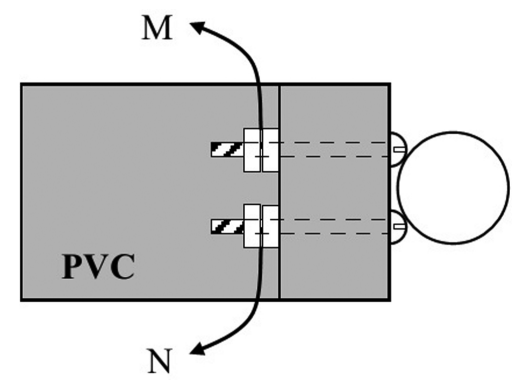

Figura 14: Vista de cima do anteparo a partir do qual a esfera é liberada no plano inclinado. 
Fig. 10 o contato NA pelo contato NF, como mostra a Fig. 15.

Os terminais de CH1 são conectados aos pontos $\mathrm{M}$ e $\mathrm{N}$ indicados na Fig. 10, enquanto os terminais de $\mathrm{CH} 2$ são conectados aos pontos $\mathrm{X}$ e $\mathrm{Y}$.

O experimento começa com a esfera de aço encostada no anteparo. Com isso, estabelece-se o contato elétrico entre os pontos $\mathrm{M}$ e $\mathrm{N}$ (Fig. 10), curtocircuitando o SCR. A corrente, inicialmente bloqueada pelo SCR, começa então a circular pela bobina. Como consequência, o contato inicialmente fechado do relê abre-se, o resistor limitador entra em ação e o marcador passa a funcionar em regime de espera. Quando a esfera é liberada, a corrente pela bobina cessa, o contato do relê volta para sua condição original (NF) e o resistor limitador é curto-circuitado, permitindo então que o marcador comece a imprimir marcas sobre a fita de papel em movimento . Quando a chave $\mathrm{CH} 2$ é fechada momentaneamente pela passagem da esfera sobre ela, o SCR dispara, a bobina é energizada novamente, o contato do relê abre-se e o marcador volta a trabalhar em regime de espera.

Neste experimento, a distância $d$ percorrida pela esfera no plano inclinado variou entre 10 e 40 centímetros. O gráfico $d$ versus $t^{2}$ (Fig. 16) ilustra um dos resultados obtidos. Enquanto nesta experiência medimos o tempo gasto pela esfera para rolar até a base do plano inclinado a partir de certa posição, na anterior, abandonando a esfera das mesmas posições, determinamos a velocidade alcançada por ela na base do plano. A Fig. 17 mostra o gráfico $v$ versus $t$ construído a partir dos dados obtidos nos experimentos 3 e 4. Se levarmos em conta pequenas perdas de energia e a incerteza quanto ao posicionamento da chave $\mathrm{CH} 2$ na parte curva da rampa, podemos concluir a partir desses gráficos que as relações entre $d$ e $t$ e entre $v$ e $t$ para o movimento do centro de massa de uma esfera, partindo do repouso e rolando

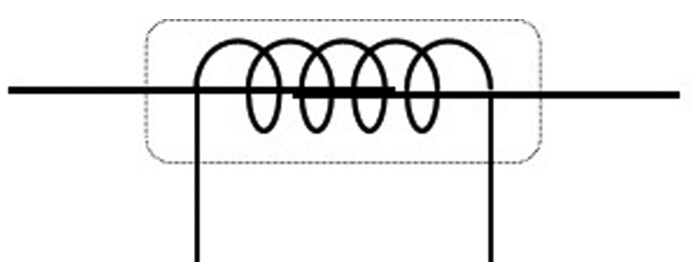

Figura 15: Relê utilizado para medir o tempo de descida de uma esfera rolando sobre um plano inclinado, onde o contato normalmente aberto (NA) da Fig. 10 foi alterado para contato normalmente fechado (NF).

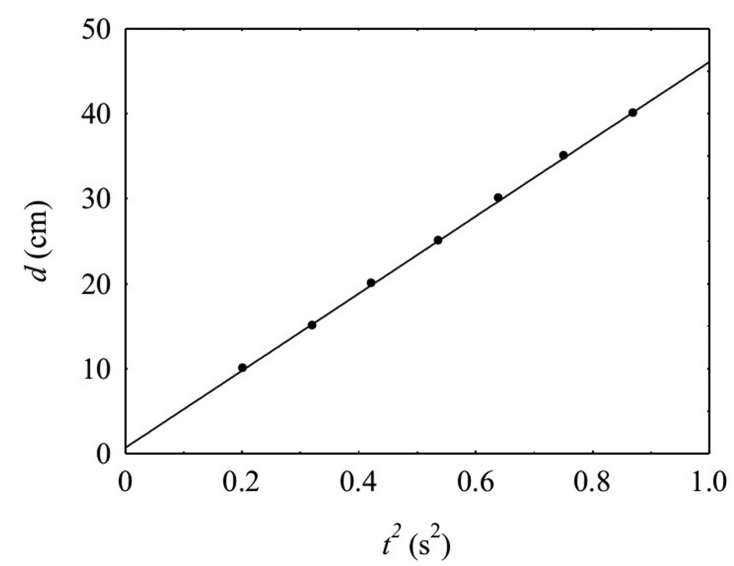

Figura 16: Distância d percorrida por uma esfera rolando sobre um plano inclinado a partir do repouso em função do tempo ao quadrado. Os pontos representam os dados experimentais enquanto a linha cheia corresponde ao ajuste linear.

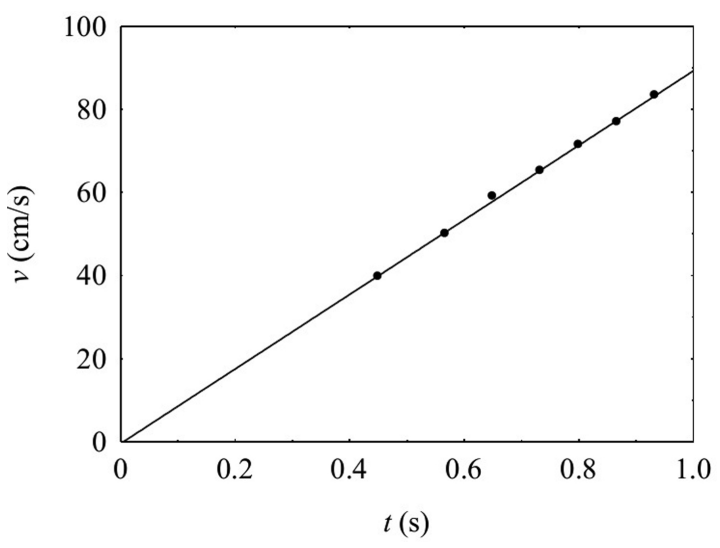

Figura 17: Velocidade v de uma esfera rolando sobre um plano inclinado a partir do repouso em função do tempo $t$. Os pontos representam os dados experimentais enquanto a linha cheia corresponde ao ajuste linear.

para baixo sobre um plano inclinado, são do tipo $d=k_{1} t^{2}$ e $v=k_{2} t$. As constantes $k_{1}$ e $k_{2}$ determinadas a partir das inclinações dessas retas são iguais respectivamente a $45,4 \mathrm{~cm} / \mathrm{s}^{2}$ e $89,7 \mathrm{~cm} / \mathrm{s}^{2}$. Como já era esperado, $k_{2}$ é praticamente o dobro de $k_{1} \mathrm{e}$ igual a metade da inclinação da reta no gráfico da Fig. 12.

\subsection{Experimento 5 - Medida da velocidade de um carrinho num trilho de ar.}

Em algumas situações é preferível utilizar uma chave óptica em vez do SCR para acionar o marcador. Suponhamos, por exemplo, que se pretenda medir a velocidade de um carrinho deslocando-se num trilho de ar horizontal. Isso pode ser feito montando-se 
uma tela opaca sobre o carrinho e determinando-se o tempo que ela gasta para passar através da chave óptica. A partir desse tempo e do comprimento da tela, determina-se a velocidade do carrinho. A fig. 18 representa esquematicamente um circuito apropriado para medir o intervalo de tempo em experiências como essa; neste circuito, voltamos a usar o contato NA do relê.

O funcionamento da chave óptica adotada está descrito em detalhes na Ref. 1, item 4.1. No esquema da Fig. 18, a corrente na bobina é controlada pelo potencial do ponto $\mathrm{Q}$, porque está conectado através do resistor de $470 \Omega$ à base do transistor BC548. Quando Q está num nível alto, o transistor conduz e a bobina é energizada; quando está num nível baixo, a bobina permanece desenergizada porque não há corrente atravessando o transistor. Por outro lado, o potencial de $\mathrm{Q}$ depende do comportamento do TIL78 (fototransistor); ele conduz enquanto há radiação proveniente do LED incidindo em sua base e deixa de conduzir quando a radiação é interrompida. Enquanto conduz, o potencial de Q permanece num nível baixo e passa para um nível alto quando a condução cessa [1]. Resumidamente, o circuito funciona da seguinte maneira: $i$ ) enquanto a radiação na base do fototransistor não for interrompida, o potencial de $\mathrm{Q}$ permanecerá num nível baixo e não haverá corrente pela bobina porque o transistor não conduz com Q num nível baixo. Consequentemente,

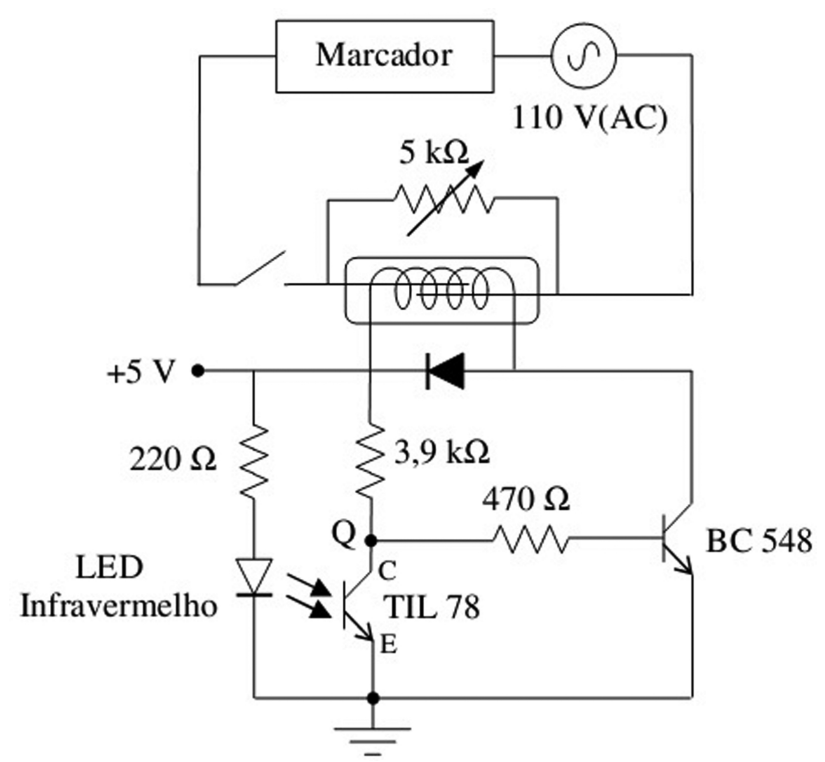

Figura 18: Esquema de um circuito para medir o tempo de passagem por uma chave óptica de um carrinho deslocandose sobre um trilho de ar. o contato do relê continuará aberto e o marcador em regime de espera, graças à ação do resistor limitador, ii) ao passar pela chave óptica, a tela do carrinho bloqueia a radiação incidente na base do fototransistor, o potencial de $\mathrm{Q}$ vai para um nível alto e o BC548 começa a conduzir. A bobina é então energizada e o contato do relê fecha-se, curto-circuitando o resistor limitador. Como resultado, o marcador começa a imprimir marcas sobre a fita de papel em movimento e iii) a impressão é interrompida imediatamente após a passagem da tela através da chave óptica, pois o marcador passa a funcionar em regime de espera.

É interessante destacar que em experiências como essa o marcador pode fazer o papel de um cronômetro com memória. Por exemplo, suponhamos que depois de passar pela chave óptica o carrinho colida com um anteparo e volte atravessando a chave óptica novamente. Neste caso, a fita pode registrar tanto o tempo de passagem na ida como na volta.

\section{Conclusões}

Descrevemos um marcador de tempo construído a partir de um pequeno compressor de ar para aquário e uma caneta hidrográfica, similar àquele utilizado pelo 'Physical Science Study Comittee' (PSSC). É um marcador de baixo custo (cerca de $\mathrm{R} \$ 50,00$ ), de fácil construção, alimentado pela tensão da rede elétrica e que opera numa frequência fixa de 60 Hz. O fato de ser alimentado pela rede e trabalhar numa frequência conhecida é uma das vantagens deste marcador quando comparado com o similar do projeto PSCC. Outra vantagem está associada à escolha da caneta hidrográfica em substituição ao disco de papel carbono utilizado em marcadores desse tipo. Descrevemos também várias experiências para ilustrar como esse marcador pode ser utilizado, quer para registrar posições de objetos em movimento, quer para medir automaticamente a duração de um evento. Dentre os experimentos propostos, destacamos o estudo do movimento de um cilindro que rola sobre um plano inclinado. A aplicação do marcador é também ilustrada em três experimentos clássicos, já bem conhecidos na literatura, utilizando uma esfera. No primeiro caso, a fita sobre a qual a caneta imprime marcas é puxada pelo cilindro em movimento; no segundo, a fita é puxada por um dos elementos da equipe que está realizando o experimento. Acreditamos que a proposta é uma 
alternativa viável para aqueles que gostariam de dispor de um dispositivo de baixo custo para usálo em aulas de demonstração ou até mesmo num laboratório didático de física básica. Os circuitos utilizados em associação com o marcador que permitiram realizar os vários experimentos sugeridos são relativamente simples e podem ser reproduzidos sem grande dificuldade.

\section{Agradecimentos}

Os autores agradecem à FAPESP (Fundação de Amparo à Pesquisa do Estado de São Paulo) e ao CNPq (Conselho Nacional de Desenvolvimento Científico e Tecnológico) pelo apoio financeiro. Agradecem também pelo apoio técnico ao servidor Leandro Xavier Moreno do Departamento de Física da UNESP/Rio Claro.

\section{Referências}

[1] R. Hessel, C.S. de Oliveira, G.A. Santarine e D.R. Vollet, Revista Brasileira de Ensino de Física 30, 1501 (2008). Erratum 31, 4901 (2009).

[2] R. Hessel, C.S. de Oliveira, G.A. Santarine, D.R. Vollet e A.C. Perinotto, Revista Brasileira de Ensino de Física 30, 1502 (2008).

[3] L.W. Taylor, Advanced Undergraduate Laboratory Experiments in Physics (Addison-Wesley Publishing Company, Inc., Massachussets, 1961).

[4] T.W. Willians, Experiments on an Air Track (Ealing Corporation, Scotts Valley, 1969).

[5] H.C. Pupo e E.C. Ziemath, Caderno Brasileiro de Ensino de Física 19, 121 (2002).

[6] M.A. Dias, H.S. Amorin e S.S. Barros, Caderno Brasileiro de Ensino de Física 26, 492 (2009).

[7] B.N. Sismanoglu, J.S.E. Germano, J. Amorin e R. Caetano, Revista Brasileira de Ensino de Física 31, 1501 (2009).

[8] Physical Science Study Committee (org), Física (Edart, São Paulo, 1968), Parte I, p. 217 e (Edart, São Paulo, 1967), Parte III, p. 162 e 184.

[9] F.D. Saad, K. Watanabe e P. Yamamura, FAI Fúsica Auto-Instrutiva (Editora Saraiva, São Paulo, 1973), v. 1, p. 155.

[10] R. Hessel e H.M. Gupta, Phys. Teach. 21, 172 (1983).

[11] R. Hessel, Revista de Ensino de Física 5, 21 (1983).

[12] U. Ingard and W.L. Kraushaar, Introduction to Mechanics, Matter, and Waves (Addison-Wesley $\mathrm{Pu}-$ blishing Company, Inc., Massachussets, 1960), item 1.4, p.18.
[13] Physical Science Study Committee (org), Guia do Professor de Física (Edart, São Paulo, 1967), Parte I, p. 70 .

[14] R. Hessel, S.R. Canola e D.R. Vollet, Revista Brasileira de Ensino de Física 35, 2504 (2013).

[15] J.S. Huebner, Phys. Teach. 23, 315 (1985).

[16] H. Cohen and D. Horvath, Am. J. Phys. 56, 950 (1988).

[17] D. Halliday, R. Resnick and J. Walker, Fundamentals of Physics (John Wiley \& Sons, Inc., Somerset, 2011), $9^{\text {th }}$ ed., chapters 10 and 11.

[18] N.C. Braga, Curso Básico de Eletrônica (Ed. Saber Ltda, São Paulo, 2001), $4^{\mathrm{a}}$ ed., lição 11. 